\section{A CLINICAL LECTURE}

$$
\text { ON A }
$$

CASE OF PSORIASIS TREATED BY THYROID
EXTRACT.

Delivered at the Ediuburgh R'syal Infirmaiy.

BY BYROM BRAMWELL, M.I)., F.R.C.P.EnIN., Assistant Plissician to the Elinburgh Royal Infirmary.

Tris patient, who has just recovered from a severe and obstinate attack of psoriasis, was admitted into Ward 5A on September 7 th, 1893 .

The disease had been in existence for three months before the patient came under my care, and for five or six weeks a variety of internal and external remedies had been employed in one of the other wards of the hospital without any alteration or improvement having taken place.

For the first week after her admission to my ward the patient was confined to bed, no treatment of any kind being employed, the object being to allow us to form an opinion as to the natural condition, so to speak, of the case.

On September 13th Brady aud Martin's extract of thyroid-5 minims once daily - was prescribed. The dose was increased to 10 minims on september 20 h, to 15 minims on September 27 th, and to 20 minims on Oetober 5th.

On 0 -tober 14th 1 drachm of Duncan and Flo:khart's extract was substituted for Brady and Martin's preparation, which had run short. This dose was rapidly increased to 5 drachms, corresponding to five eighths of a thyroid gland daily. This dose was continued from November 8 th of a thy

On Norember 25th Burroughs and Wellcome's tabloids were given in On November 25th Burroughs and Wellcome's tabloids were giren instead of Duncan and Flockliarts liquid preparation, the dose being rapidly increased from 1 to 5 tabloids. From

patient took 5 tabloids (=to , of a gland) each das. attack of influenza. 1t was resumed again on January 2 nd. The eruption had entirely disappeared on January 14th.

The following notes show the result of the treatment: September 14th the day after the commencement of the treatment). There is no change in the condition of the eruption. September 19th. Some scales are be cinning to separate on the back and abdomen; there is no change on the (1) eruption is less scaly and red; on the head the crusts are breaking aud cracking, and look as if they are about to be detached ; there is no change on the 10 September 27 th. The eruption is less extensive, but the improvement is slew. October 5 th. Still improving, more especially on the back ment is slow. October 5 th. Still improving, more especially on the back; there is little change on the limbs; the scalp is much clearer. Oetober 14th. The improvement still continues, but it is very slow. (Duncan and Flockhart's extract commenced.) Octoben 20th. Eruption much in was encased in cotton wool. The photographs represented in Figs. and 2 were taken on this day.

My reason for covering up the arm was this. A short time previously I had been asked by $\mathrm{Mr}$. Caird to see a patient who was suffering from a very severe psoriasis of some thirteen years' duration. The eruption was diffused, not in the form of isolated patches, but uniformly over almost the entire body. The patient was admitted to the Infirmary on account of a fracture of the leg. Thinking that the case would be a good test case for the thyroid treatment, Mr. Caird kindly asked me to see it with him. I entirely agreed with his opinion. The thyroid treatment was accordingly commenced forthwith, thirty drops of Brady and Martin's liquid extract being given to the patient each day. In the course of a fortnight a marked improvement had taken place in the condition of the skin, a profuse desquamation of small scales being produced. About this time the leg was examined in the ordinary course of surgical procedure, and a very curious thing-and this is the point I wish you to note-was observed. On removing the splints, the whole of the skin on the front of the leg became detached with the cotton wool in the form of a large scale; it measured 8 inches in length, by $4 \frac{1}{2}$ inches at its broadest part.

It occurred to me that it would be worth while trying whether the detachment of the scales in other cases of psoriasis might not be hastened by the same procedure. This girl's arm was therefore covered up, as shown in photo. graph 1, first with ordinary cotton wool, and then with salicylic cotton wool. The experiment was not a success. On November $17 \mathrm{th}$, when the salicylic cotton was removed, the uncovered arm looked the better of the two (see Fig. 3). The arm, which had been protected from the atmosphere, was thickly covered with dense white scales, which were loose and yuite easily detached. The photograph represented in Fig. 3 shows the appearance.

The cotton wool was not reapplied; and in the course of a few days both arms were practically in the same condition, the loose scales on the left arm having become detached.

The only effect produced by covering up the arm seemed to be the retention of the scales. On the uncovered arm the sca'es were detached as soon as they became loose: on the covered arm they were retained. Consequently, when the cotton wool was removed at the end of three weeks, the left arm appeared to be worse than the right.

November 2uth. Milk diet was to-day ordered, and a dose of cascara each night prestribed, as the bowels have of late been constipated.

November 2.th. There lias been little or no improvement since last note. On the head and face the disease is worse, a new crop of seales having developed during the past month. Inmely, during the time that having developed during the past month. Ininely, during the time that the patient was taking the dilute liquid extract. (I am strongly inclined this diluted extrait. I sliall refer to this point again presently.) Tabloids to be substituted for the liquid extract.

Tabloids to be substituted for llie liquid extract.
November $2 \%$ th. The milk diet was discontinued, as the patient says that she is very hungry, and that it does not satisfy her. To have convalescent diet: fish, chicken, etc., but no butcher's meat.

December 3rd. A marked improvement has occurred since the tabloids were commenced : the scales of eruption are being detached from the back, arins, and front of the trunk.

Deceinber luth. The improvement continues. All parts of the body look much better.

December 17th. Rapidly improving.

December 2ttli. Face, back and front of the trunk almost clear; arms greatly improved; legs also much better.

December 29th. The patient fecls very sleepy, and complains of headache and sore throat. The tongue is furred; the temperature $101^{\circ}$ : the throat and plarynx are red and iujected. The febrile attack was diagnosed as intlueura there lave loen several cases in the ward. The thyroid treatnent was discontinued, and three grains of quinine with five grains salicylate of soda every four hours were ples(ribed. The oceurrence of the influenza is unfortunate, for the skin disease is almost well.

December 31st. The attack of influen\%a has been a slight one; the temperature is to-day normal; the patient feels weak, but otherwise vell.

January 2nd. The thyroid treatment was resumed, 5 tabloids per diem. On this day I had the pleasure of showing this and some other patients who were under the tliyroid treatment to Drs. Crocker, Allan Jamieson, and Norman Walker. The back, face, arms, and front of the trunk were practically clear. The head was still thickly covered with dry, mortarpractically clear. The head was still thickly covered with dry, mortarlike crusts, but they were loose : the scalp underneath was quite clear and healthy. The legs are still covered with copious small ecaly patclies. Dr. Cro

January ofth. The face, back, front of the trunk and arms have been January lith The face, back, front of the trunk and arms have been
quite clear for the past week, and the legs are now free from scales. On
the arms and legs the skin is quite smootli and healthy, but pigmented at those places where the eruption previously existed.

In this, as in the first two cases in which I tried the remedy, not only did the eruption disappear, but the skin was left, in a beautifully soft and healthy condition. On January 17th the patient was shown to the Medico-Chirurgical Society. On January 2 ith the photographs, which are reproduced in Figs. 4 and 5, were taken.

The final result in this case has been very satisfactory. The cure must, I think, be chiefly attributed to the thyroid treatment. The case was an obstinate one, and the improvement was effected much more slowly than in some of the other cases in which I have employed the remedy. A change for the better was indeed noticed almost immediately after the thyroid treatment was commenced, but the improvement during the first month of the treatment, during the time that the patient was taking moderate doses of Brady and Martin's liquid extract, was not great. During the next six weeks (Duncan and Flnckhart's more dilute extract) there was no improvement ; in fact, a fresh crop of eruption appeared on the scalp. The patient was then placed on milk diet; after four days the milk diet was discontinued, and convalescent diet, a daily dose of cascara and the thyroid tabloids were prescribed. From that date a very marked and rapid improvement occurred, and in the course of $a$ month the patient was practirally well.

It is, of course, impossible to say definitely and 1 ositively how much of the suciess ought to be attributed to the change in diet and to the careful regulation of the bowels, and how much to the thyroid treatment. All three were probably effective, but the chief credit must undoubtedly, I think, be given to the thyroid treatment. Although in some cases a psoriasis disappears after a change of diet, such a result is quite exceptional. In this very obstinate case the change of 
diet and the regulation of the bowels probably lielped the treatment, and enabled the thyroid extract to take effect. In the course of a month the cure was practically complete. no local remedies of any kind having from first to last been applied to the surface of the skin.

In this case the solid thyroid tabloids proved more efficacious than the liquid extracts, and the strong extract more efficacious than the more dilute extract. I have had the same experience in other cases. I am disposed to think that the solid extract in the form of tabloids is the most effective and reliable preparation which has as yet been produced." I am inclined to think that the active principle is apt to become weakened and deteriorated in the liquid extracts, and that the more diluted the liquid extract the more rapidly does this deterioration take place.

I was induced, as I stated in my previous paper in the BritisH Medical Journal of October 28th, 1893, to try the thyroid treatment in psoriasis because I had noticed that in some cases of myxœdema a very marked desquamation of the skin occurs during the process of cure. In the first case of myxœdema which I treated by thyroid feeding the skin peeled off from the hands and feet, just as it does after a severe attack of scarlet fever. The very profuse desquamation which took place in that case (see Fig. 6) was, I believe, due to the large doses of the fresh thyroid gland which were employed. Vesquamation has occurred in every case of myxcedema and sporadic cretinism (see Fig. 7), in which I have had the opportunity of carefully observing the effects of the thyroid treatment. It has never been so profuse as it was in my first case ; in fact, in most of the subsequent cases it has had to be looked for; but it has always been quite noticeable. when looked for, on the heels.

2 Solid tabloids are made by several che nists-Messrs. Duncan and Flockhart; Allen and Hanburys; Burrouyhs, Wellcome and Co.; etc.
The remedy is of undoubted value not only in psoriasis but also in lupus and ichthyosis, possibly also in exfoliative dermatitis, and perhaps in other varieties of skin disease as well. Fortunately the first case of psoriasis in which J employed the remedy improved straight away in a most remarkable way. I say this was fortu. nate, for, as I shall afterwards have to tell you, some cases of pso. riasis do not seem to be beneficially affected by the remedy, and, had I chanced to begin with one of them, I might perhaps have hesitated to continue the trial. My first case of psoriasis was exhibited at a meeting of the Medico-Chirurgical Society of Edinburgh, which was held on February 16th, 1893, for the purpose of dis. cussing the subject of myxodema. ${ }^{3}$ Dr. Arthur Davies, who happened to be present, was so much struck with the result which had been produced in the course of a few days' treatment that he determined to try the remedy when he got back to London. He has since published some cases confirmatory of my results.

The photographs showing the results in my two first cases were published in the BRITISH MEdical JoUrNAL of October 28th, 1893. When I last saw these patients (six months after their discharge from hospital) they were both absolutely well. In both cases the skin of the entire body was beautifully soft and healthy, like that of a baby. In the first patient one little spot of psoriasis, the size of half a pea, had developed on the left elbow ; it appeared shortly after the patient's discharge from hospital, but it has remained stationary in size, and no new patches have developed since.

The three cases in which the result has been so successful have been treated in hospital. I am disposed to think that confining the patients temperature-is, perhaps, an important adjunct to the 
treatment. Some slight cases of psoriasis which I liave treated as out-patients have not improved, or have for a time improved and again relapsed. It is possible, I think, that one reason why out-patients do not improve is that they go about and expose themselves to changes in temperature and weather, and that that, perhaps, to some extent interferes with the therapeutic edfect of the remedy. But that is certainly not the only explanation of the failures; for in three cases which I have treated in hospital the remedy did

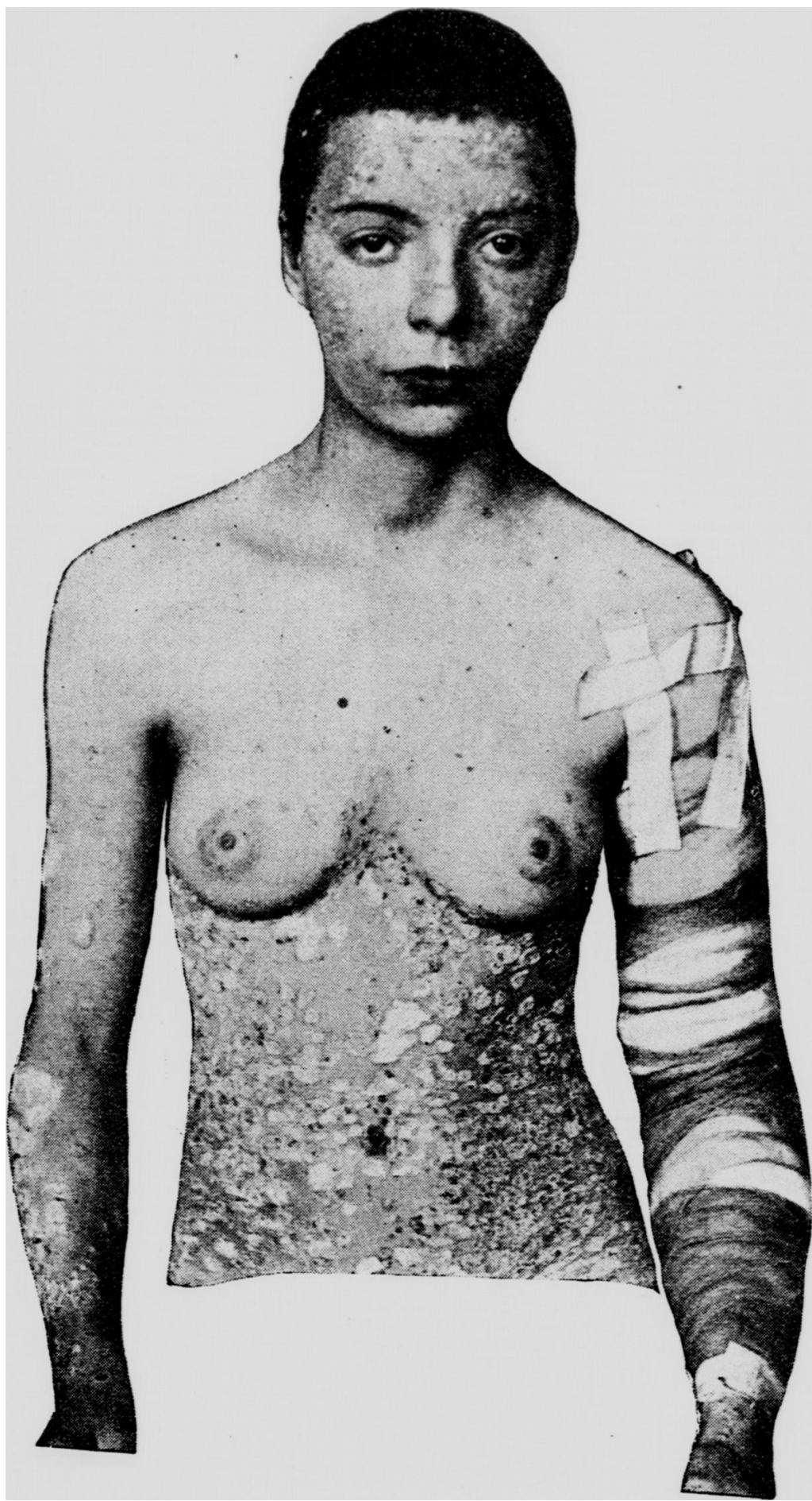

Fig. 1.-The case of psoriasis described in the text. Front view, showing the condition on October 27 th.

not effect a cure. One of these, the third case reported in the British Medical Journal of October 28th, 1893, improved remarkably for a time, and then relapsed. Another, a comparatively slight case, did not seem to derive any material benefit from the treatment.

I do not say that thyroid extract is a specific in all casc $s$ of psoriasis, but I do deliberately say that it is a most efficacious remedy in some cases of the disease. A man who claims to obtain therapeutic results, which the subsequent experience of independent observers fails to confirm, necessarily and deservedly loses credit and comes to be looked upon as an untrustwortly observer. I have no wish to place myself in that position. My experience enables me to say detinitely that some case's of psoriasis can be cured by thyroid extract, and by thyroid extract given alone. In all of the cases in which I have employed the remedy, absolute!y nothing has been applied to the skin. All the cases which I have published have heen treated in a public hospital, and closely watched by many independent observers. In the first two cases no change was made in the dietary. In the

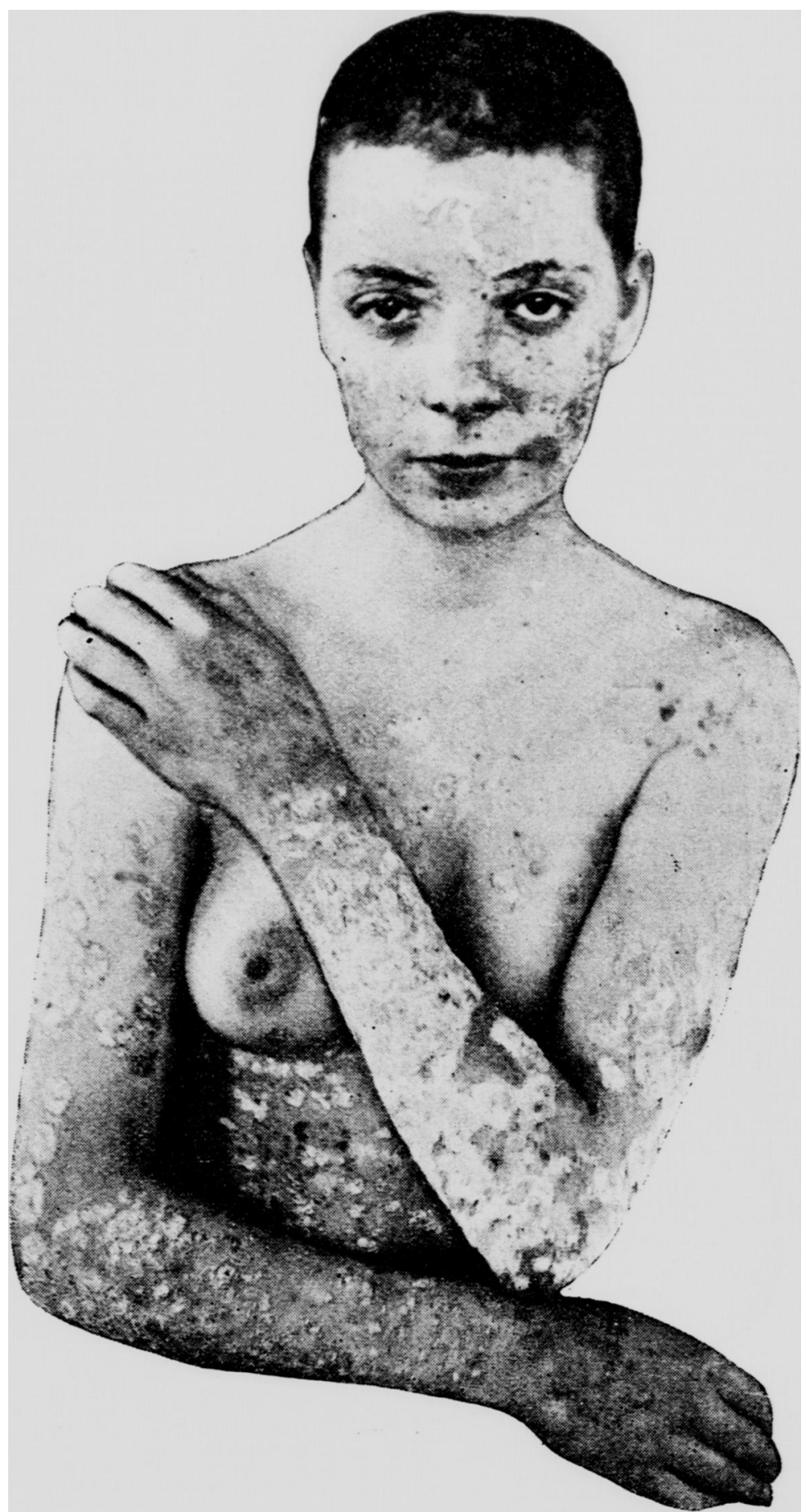

Fig. 3.-The case of psoriasis described in the text, showing the condition of the left arm on November 17 th, after it had been covered up for three weeks in salicylic wool.

case which I have brought before your notice to-day a change in diet was made before the improvement commenced. It is probable, I think, that that change may in some degree have helped the treatment, but for the reasons I have already given you I believe the successful result must be chiefly attributed to the thyroid treatment.

I have some other cases of psoriasis under observation. both as out-patients and in private practice. In some of them the treatment has been successful, but I do not propose to enter into details regarding all of these cases on the present occasion. . The results in every case in which I have 
employed the remedy, whether successful or the reverse, will be published in due course. I repeat that, as the result of my own observation, I an disposed to think that in some cases of psoriasis the thyroid extract exerts such a rapid and beneficial etfect, that, for them, it may without any exaggeration be termed a specific, but that in other cases the effect is comparatively slight, and that in some cases the remedy siems to be useless. But whether the last conclusion is correct or not, I unhesitatingly affirm that thyroid extract is a

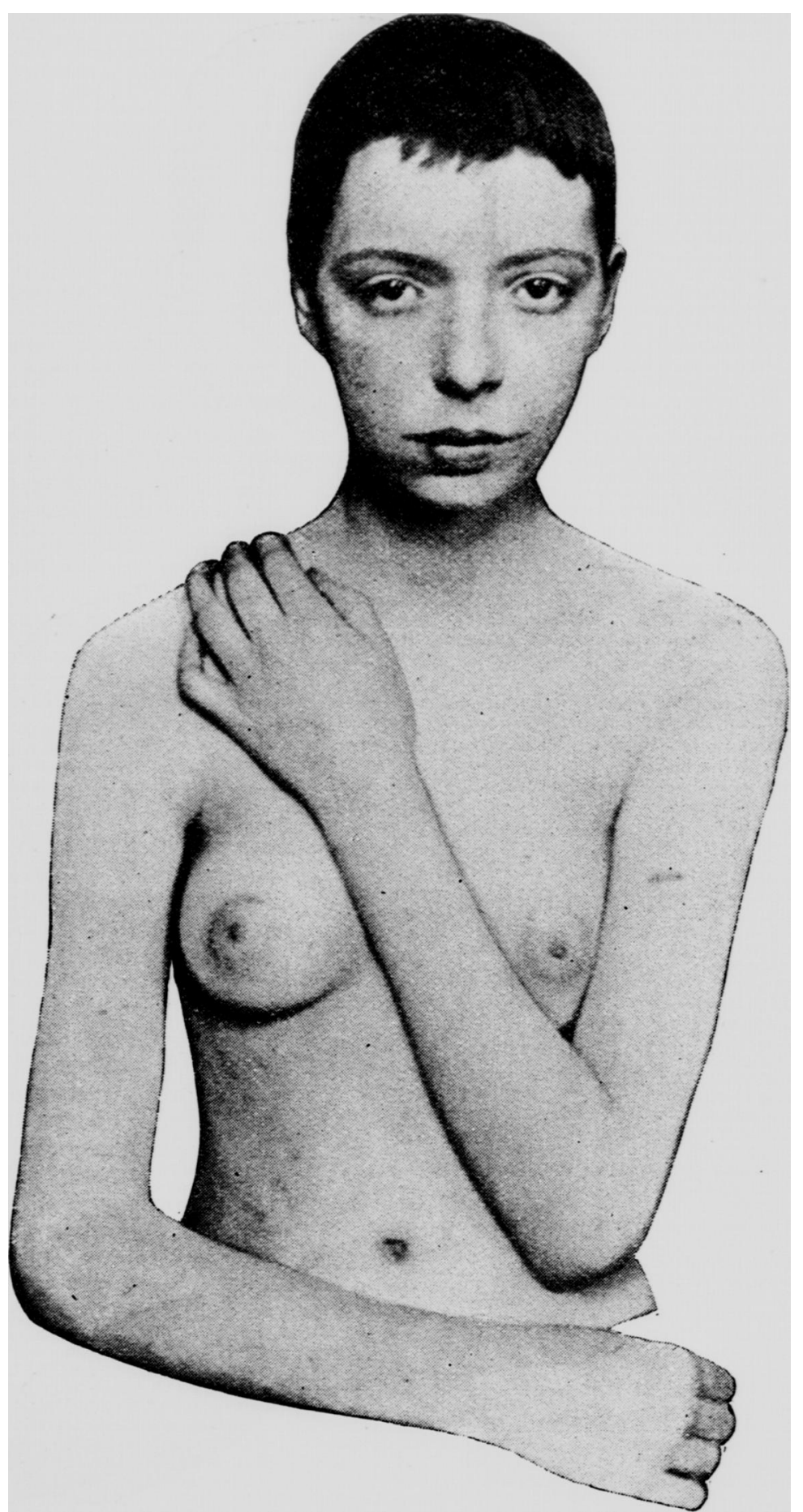

Fiz. 4. -The case of psoriasis described in the text. Front view showing the condition on January eoth.

most valuable addition to our means of treating psoriasis. I fancy that the quickest way of curing most cases of psoriasis would be :- to confine the patients to an equable temperature, either in their own homes or in the wards of a hospital ; to give them a milk, fish, chicken diet (that is, a diet from which sweets and red meats are excluded); to regulate carefully the condition of the bowels : to apply locally some of the external remedies which experience has shown to be useful in the treatment of the disease : and to administer intermally the thyroid extract or. preferably, thyroid tabloids, in as full doses as the peculiarities of each case will allow. The last part of the treatment is, perhaps, the most important.
In the cases which I liave published nothing has been applied externally, for the simple reason that I am tresting a new remedy, and $I$ do not want to conplicate my experi. ments. My object has been to determine whether the thyroid extract exerts a beneficial influence upon psoriasis and other skin diseases. Now, if this is so, if thyroid extract can cure some severe case's of peoriasis without any external application, it is only reasonable to suppose that it will facilitate and hasten the cure of the disease when combined

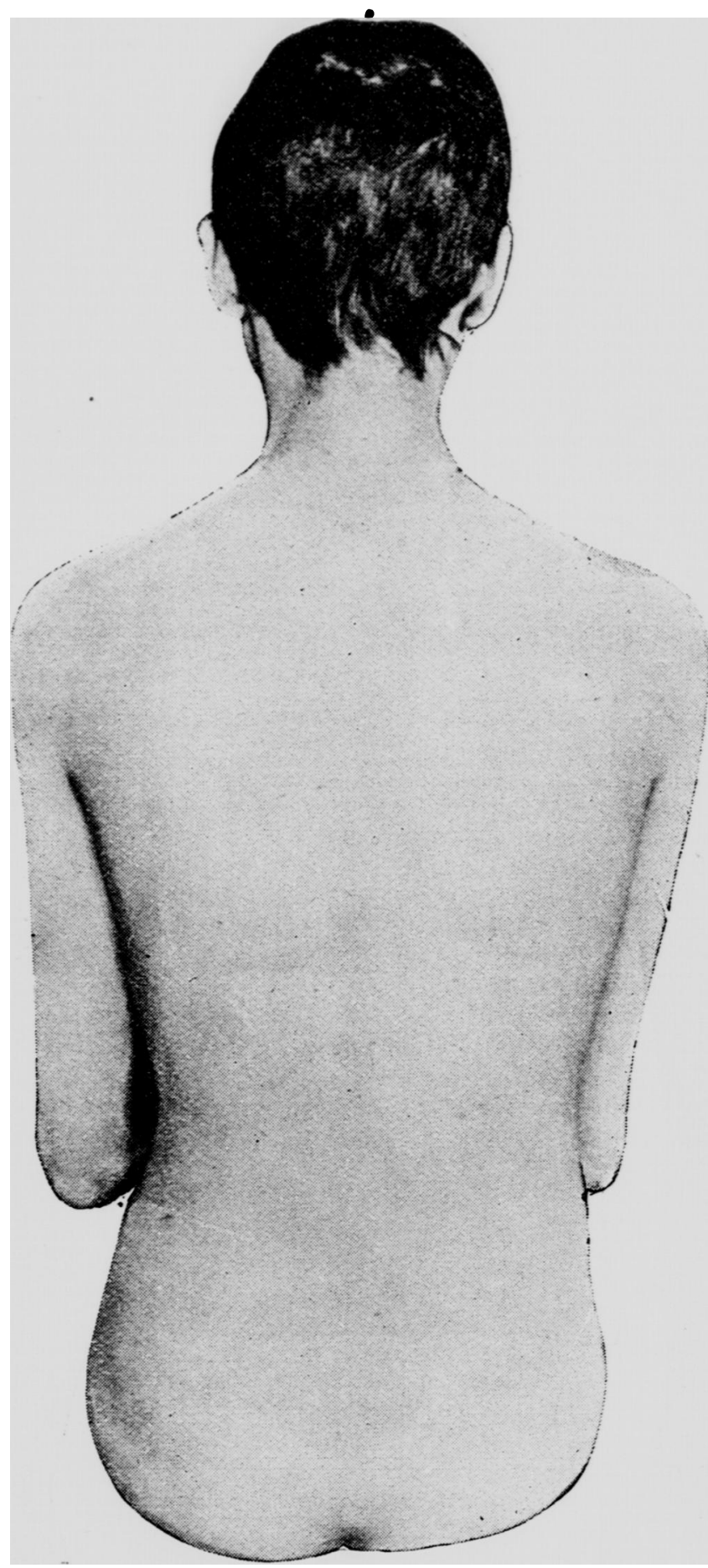

Fig. 5.-The case of r,oriasis des(')ibed in the text. Back view showing the condition on January 2 th.

with local treatment and external remedies which experience has shown to be beneficial. In other words, cases which do not yield to internal treatment alone, and cases which do not yield to external treatment alone, will be more quickly cured by the combined use of thyroid treatment internally and local remedies externally than by either method of treatment separately. I think it is quite possible that in some of the cases which have been reported, in which a speedy cure was effected by external or other internal remedies (such as arsenic) after the thyroid treatment had apparently failed, the preliminary course of thyroid extract 
may have paved the way, as it were, for the action of other remedies, and in reality falcilitated the cure.

In what proportion of cases of psoriasis the thyroid extract rill cure the disease without the aid of any external applications I am not prepareel to say. My observations are at present quite insufticient to allow of any reliable statement on this point.

A number of observers in different parts of the world are giving the treatment a trial. I have received a large number of inquiries regarding the thyroid treatment from medical men, not only in this country, but abroad. Some 'observers have already published their results. Some have'been successful with the remedy, some have not. Dr. Abraham, who was one of the Secretaries to the Dermatological Section of the British Medical Association, in which I read a paper on the subject at the Newcastle meeting, has not had much success, but his patients were out-patients, and, from the statement which he has published, I am inclined to doubt whether he employed the remedy with sufficient perseverance and in sufficiently large doses to get the best results.

The case which I now record shows that some cases only yield to the remedy after large doses have been given for long periods of time. From the observation of this and other cases, I have come to the conclusion that the best method of giving the remedy in cases of skin disease is to give as large doses as each individual patient can bear some patients can take much larger doses than others. The problem is to determine, in each individual case, the maximum dose of thyroid extsact (in the form of liquid or, preferably, I think, in the form of tablcids) that the patient can take without being upset. The best therapeutic guide to the dose which each patient can take is, I think, the con. dition of the pulse. In cases of myxcedema and sporadic cretinism thyroid extract raises the temperature and pulse, and, when given in large doses, is apt to produce profound depression, headache, aching pains in various parts of the body, nausea, vomiting, gastro-intestinal disturbance, and diarrhœe. In healthy persons, and in patients who are suffering from psoriasis and many other skin diseases (lupus, ichthyosis, etc.), larger doses can usually be given (than in myxœedema) without producing any bad effects. Many patients who are suffering from skin diseases can take a quarter of a gland daily for long periods of time. A larger dose than this usually raises the pulse above 100 or 110 , and is apt to produce headache, nausea, gastro-intestinal disturbance, etc. In a remarkable case of ichthyosis which is in the ward, and about which I shall have a good deal to say on some future oc'asion, large vesicles and inflammatory patches were produced on the surface of the body. But in that case a very large dose was given (60 minims of Brady and Martin's extract, and 4 of Burroughs, Wellcome, and Co.'s tabloids every day). In that case 60 minims of Brady and Martin's extract produced no increase in the pulse rate; it was not until 4 tabloids were added to the extract that the pulse rose in frequency, the stomach became upset, and the inflammatory lesions in the skin were developed. I would advise you, then, in cases of psoriasis and other skin diseasesj to take the pulse as your guide, to begin with small doses, and to increase gradually the dose until the pulse reaches 100 or 110 , and then to stop. A larger dose than this is apt to upset the patient (that is, to cause headache, gastro-intestinal catarrh, vomiting, suppurative lesions in the skin, etc). If headache, nausea, and vomiting or other untoward symptoms are produced, the dose should be reduced immediately, or the remedy suspended altogether for a few days. I have not found that it is necessary to decrease the dose when an increase in the puls. rate is the only manifestation of thyroidism, Provided that the pa tient feels quite well that the appetite keeps good, and the tongue re'mains clean, the remedy may, so far as my pri sent experience enables me to judge, be continued, even although the pulse rate is 100 or 110.

Having found by experiment, as it were, the maximum dose which each individual patien: can take, the remedy should be persistently given for long periods of time. In cases of psoriasis and other forms of skin disease, it is premature, I think, to conclude that the treatment is a failure, unless the maximum dose which the patient can take has been given for at least a couple of months : and in some skin diseases - lupus, for example-a much longer period than this may be required to produce any very decided effect in the way of cure. In one of the cases of lupus which we have in the wards, the patient has been almost continuously under the thyroid treatment, either in or out of hospital, for twelve months.

In some cases of psoriasis there is no improvement until distinct symptoms of thyroidism are produced; a rapid and continuous improvement then results. (I append at the end of these remarks the notes of a case in point.) This is a very impertant point; it is only what one might expect, for the full therapeutic effect of many remedies is not observed until their physiological effects are produced. 
I expect that in a considerable percentage of cases of psoriasis a marked improvement, and in many cases a complete cure, will take place, provided that the remedy is given in the way I have just described-the maximum quantity that the patient can bear, administered every day persistently for a couple of months or longer, the patient being confincel to bed, or, at all events, to an equable temperature during the course of treatment. Is I have already stated it is premature to conclude that the remedy is a failure until the therapeutic action of the drug (thyroidism) is produced. It is impossible that the cures which I have obtained can be mere coincidences. The immediate improvement which is produced in some cases conclusively shows that the thyroid extract exerts a most marked beneficial effect in some cases of the disease; but, as I have already said, I do not claim that this beneficial influence is produced in all cases. The different effects which the thyroid extract produces in different cases of psoriasis will perhaps be a means of enlarging our knowledge of the disease. There must be some explanation of the fact that, in some cases, an immediate and markedly beneficial effect is produced, while in others there is little or no improvement; indeed, in some cases, the disease is said to have been aggravated by the treatment, for in some of the cases which have been reported the eruption extended and increased after the administration of the remedy. Whether these differences are due to actual differences in the character of the disease, or merely to differences in the soil (the constitution and temperament of different patients) on which the disease (the psoriasis) is, as it were, engrafted, I am not at present present prepared to say. I suspect that in some cases, in which the eruption extended and the disease appeared to be aggravated by the treatment, the extension was only the beginning of a cure; and that, if the remedy had been persisted with, improvement and cure would probably have followed. One effect of the remedy seems to be to quicken the functional activity of the skin. In some cases of psoriasis large flakes of skin are desquamated during the process of cure. It is, I think, quite possible that in some cases the first effect of this increased nutritive activity of the skin is the enlargement of the patches-in other words, a temporary, but merely apparent, increase in the severity of the disease. So far as my present experience enables me to judge, actively developing cases are much less amenable to the treatment than old standing ones in which the eruption is stationary.

I have said that different individuals react to the thyroid extract in a very different way; some persons are exceedingly susceptible to the drug. In a case of myxodema which I had repeated opportunities of seeing with Dr. David Menzies, one-eighth of a tabloid-equivalent to $\tau_{2}$ of a gland-produced a profound reaction-a rise in temperature to the extent of a degree or a degree and a-half, increased rapidity of the pulse, flushing of the face, profuse sweating, and great prostration. This result was repeatedly observed within half an hour of the administration of the remedy. It was so remarkable, that on different occasions the dose of thyroid ( $r^{\frac{1}{2}} \mathrm{~s}$ of a gland) was given to the patient without her knowledge with exactly the same result. The remarkable idiosyncrasy which this patient exhibited is fortunately quite exceptional ; but it shows that large doses of the remedy should not be rashly prescribed. Dr. Menzies told me that he believed a large dose would have killed this patient, and $I$ am disposed to agree with him.

NoTe. - The thyroid treatment of lupus and ichthyosis will be considered in future communications.

\section{ADDENDUM}

Notes of a Case of C'hronic Psoriasis C'ured by the Thyroid Treatment ; the Improvement being coincident with the production of Thyroidism - the Physiological Effect of the Remedy.-Mrs. A., aged 51, was sent to me by Dr Lennox, of Dundee, suffering from a severe 51 , was sent to me by Dr. vears' duration. The eruption was more or less diffused over the ivhole body, the face, palms, and soles being, however, spared. It consisted of scaly patches of a deep purple-brown colour. The patches varied in size from a sixpence to the size of the hand, or even larger, the largest being situated on the sacrum and adjacent parts of the buttocks, the sides of the abdomen, and the calf of the right leg.

The patient had been treated by several difterent medical men, and by a variety of external applications and internal remedies (see Dr. Lennox's She was occasionally troubled witl condition of the patient was good. was not gouty. There was no hereditary tendency to gout, psoriasis, or: other constitutional disease in her family. The disease had appeared after the cessation of menstruation.

I wrote to Dr. Lennox advising thiat a thorough trial should be given to the thyroid treatment. At the same time, I expressed a doubt whether it would be efficacious in this particular case. The long duration of the disease (three and a-half years), the obstinate way in which it had re(dark purple colour dry, with few seales), led me to think that the result might be unfavourable The chararter of the eruption closely resembled that which was present in the third rase which but the thyroid treatment for a time produced a marked improvement, the the thyroil treatment for a

On November $: t h, 1843$, D). Lennox wrote me to say that the treatment had not as yet produced any substantial effect in the way of cure, but that had not as yet produced any substantial effect in the way of cure, but that
the redness and itching were distinctly less. I replied advising him to increase the dose, and give the remedy a further trial.

I heard no more of the case until the end of January, when I had the opportunity of seeing the patient with Dr. Lennox, at Dundee. The eruption had then en

The following letter which Dr. Lennox has kindly sent me gives full details with regard to the history and progiess of the case

$$
\text { “144, Nethergate, Dundee. }
$$
January 21th, 189!

"Dear Dr. Bramwell,-In accordance with my promise made when you called the other day, I give you a summary of my notes on a case of psoriasis treated by thyroid gland preparations. The first appearance of psoriasis in Mrs. A. was in May, 1889. At that time papules, with seale on a hyperamic base, developed on the olecranon aspect of the elbows and on the extensor aspect of the legs. Gradually but continuously the disease extended both in severity and extent. One year and a-half ago the trunk and scalp were invaded; and at the time of being placed under thyroid treatment the whole body was affected, with the exception of the
face, palms, and soles. At first the papules were distinct, but soon they became in many place confluent, forming patches of greater or less ex the front, outer, and posterior aspect of the middle of the right leg and over the sacrum. The former measured 7 inches vertically (that is, in the axis of the limb) and $\tau_{\frac{1}{2}}$ inches in the circumference of the limb; the latter 8 inches vertically and $7 \frac{1}{2}$ inches horizontally. Under the patch on on the leg slight varicosity of the veins could be observed. The scales, at first like tissue paper, became latterly a thick scruff, and the subjacent hyperæmia passed from a bright red to reddish brown. Itching was a co

of sleep.

"The family and personal histories of the patient indicated a tendency in the nout, nor has another case of psoriasis been known in the family, although dryness and itching of the skin is not uncommon. Apart from slight manifestations of rheumatism, the patient's health has
been always good. All the organs of the body are healtliy. The menopause had just been completed shortly before the psoriasis appeared. The patient, although stout, is very temperate and careful of lier diet and has always strict]y avoided alcoholic beverages. She attributes her illness to an emotional shock she had in April, 1889 , and whatever significance, if any, is to be attached to this, it is certain that during the course of the disease she had been subject to much mental anxiety. A tendency to nervous diarrhoea and an undue susceptibility to the action of neurotic drugs are peculiarities of her temperament, indicating her constitutional condition.

"Since the commencement of her illness medical treatment has been almost constantly persisted in At first alkaline tonics were given internally and emollient applications used externally. Afterwards, when the disease had become established, preparations of tar were employed, such as ung. picis liquidum, $\beta$ naphthol, and liquor carbonis detergens. Then, alkaline baths of carbonate of potash were used in conjunction
with the application of oleum deelinæ. These signally failed, and chrysophanic acid was tried with no better result. Meanwhile arsenic was given internally, and pushed to its full therapeutic effect.

"In September, 1890, Dr. Allan Jamieson, of Edinburgh, was consulted. He recommended washing the parts with Unna's overfatty potash soap, followed by an ointment of chrysarobin, liquor carbonis detergens, continued. During the summer of $1891 \mathrm{Mrs}$. A. tried a course of waters continued. During the summer of 1891 Mrs. A. tried a course of waters at Strathpeffer, and again in 1892 . Feeling herself no better, she tried Bath in 1893, but without much benefit. After this, mercurial inunctions were persevered with for some time, and an elastic bandage was worn over the affected part of the right leg. And finally, before adopting the carbolic acid and liquor carbonis deteryens

"It was under these circumstances that she was sent to consult you on October 6th, 1893, when you recommended fivedrops of Brady and Martin: thyroid extract to be taken twice a day, special precautions being observed to obtain fresh supplies. This she did, as reported in my letter of November 8th, increasing the doses up to twenty drops twice daily without much effect. A slight reduction in the hyperamia and a variable relief of the itching were distinctly noticed. Following your advice in your letter of November (th, an increase in the dose of thyroid was given. For a fortnight she tried thirty drops twice a day, and then forty drops. For a fortnight she tried thirty drops twice a day, and then forty drops. painted with collodion. No definite result followed.

By this time the patient was losing confidence in the treatment, and I was inclined to believe that the therapeutic virtue of the thyroid gland would be better preserved by the process employed in making tabloids than by that in making extracts. Moreover, I was determined to pro-

"Accordingly, on December 9tl, the patient was given four of Burrouglis, Weliccme and Co.'s thyroid tabloids. Next day thyroidism was present. The patient was suffering from dyspnoa and palpitation. She was languid and easily fatigued, and her pulse was 103. On the 11th 
single tabloid was given, but, the pulse keeping about 100 and the other armptoms being still marked, the drug was stopped for four days until the pulse had fallen to $x 0$ and the dyspncea allayed. Tro tabloids were the piven for two daj's, the pulse rising to (w. since that time only one then has been administered eacl day buring the first fortuight of treat in never failed, but since then she has entirely regained her lisual appear ance. The patient was allowed out of bed on December 21 st, and hits been going about her customary avocations ever since.

so much with regard to her general condition under the thyroid tabloids; now with regard to the psoriasis. (On locember luth, that is to say the day when the thyroidism manifested itseli, the itching was greatly reduced. In a day or two the hyperienia beciune more dull, and then the scruff, which had always re-formed when it was removed, ceased to reappear. In each pateh the same sequence of events took place. The itching was first lost, then the redness, and eventually the scruff. Inprovement everywhere has been general and rapid. The smaller spots pielded first and the largest patch has been the last to go. And now only blotches of pigmentation mark the sites of the patches of psoriasis nd these blotches themselves are daily becoming less distiuct. The tabloids are still being given.

"I may add that at first the diet in Mrs. A.'s case was restricted to plain food with no condiments, and an injunction was given to partake of animal food spariugly; but during the treatment with the thyroid tabloids ordinary diet was allowed in any proportions the patient thought fit to take. Her appetite was always good.

"I regret that, owing to a natural reluctance on the part of the patient, I ain unable to furnish you with photograplis or drawings of the case.

$$
\text { "Believe me, }
$$

"Faitlifully yours,

"D. LENNox."

\section{THE LUMLEIAN LECTURES}

ON HEART INFLAMMATION IN CHILDREN.

\author{
Delicered before the Royal College of Physucians.
}

By OCTAVIUS STURGES, M.D.CAntaB., F.R.C.P., Senior Physician to the Hospital for Sick Children, Great Ormond Street and to the Westminster Hospital.

\section{III.}

Mr. President, Fellows, and Gentlemen,-In the last lecture we were led to consider the service of percussion in estimating the area of cardiac dulness at various ages and in several conditions, together with the manner of the heart's displacement with the gradual increase of pericardial fluid.

The earlier physical signs of endocarditis were then discussed, and the opinion was expressed that these signs, varying widely in various cases, and feebly expressed by words, become significant in their combination and by the comparison of to-day with yesterday. Finally, examples were given both of the sudden and of the gradual development of morbid sounds, mitral murmur occurring not seldom as the sequel, and not the accompaniment, of a child's first rheumatic attack of short duration and no severity. It remains to consider some further signs of endocarditis referable to the right and uninflamed side of the heart; to estimate the nature and frequency of mitral narrowing in the child as compared with the adult; and, in conclusion, to add but a few words on prognosis and treatment.

Endocarditis does not at first, we say, produce regurgitation or at least does not produce it by any defect on the part of the mitral valve itself. Muscular incompetence and the share in closure belonging to the muscular fibres surrounding the mitral orifice are laid out of the case. Yet, inasmuch as endocarditis concerns the fibrous structure of the left side of the heart and extends to the papillary muscles and their tendinous cords, it is of necessity that this inflammation should produce effects beyond the valve itself. And the effect is this: The muscular weakening of the inflamed left ventricle impedes the onflow of blood and tends to engorgement of the pulmonary vessels. This in its turn reflecting on the right ventricle, as Sibson points out, leads to accumulation of blood therein, which is relieved by tricuspid reflux -what has been called "safety-valve" action. If this be so, it follows that in endocarditis it is not the left and inflamed side of the heart that will give the first note of suffering; it is the right and uninflamed side, and tricuspid murmur is the early signal of inflammation as well as a token of relief.

There are some obvious reasons why this early occurrence of tricuspid murmur should often be overlooked, such as the presence of old valve murmur; the short duration of this sign and the speedy oncoming of a louder mitral murmur to drown it. It is only, therefore, in a first attack of rheumatism, and with the happy chance of early observation, that tricuspid murmur gets noticed. Something also must be allowed for the habitual neglect of the right side of the heart in the affection we are discussing, neglect lue to the knowledge that the actual seat of disease is assuredly the left ventricle not the right. Yet with all this allowance, it may still seem that, upon the hypothesis, tricuspid murmur should be met with more often than it is as an early sign of endocarditis.

'The explanation is, I think, that there is a concurrent or even a yet earlier effect of endocarditis, namely, disturbed action and rhythm of the heart. However early the transmitted effect of left-sided endocarditis upon the right ventricle, the immediate effect as regards the left ventricle itself must be earlier still. This effect is no other than an irritability of the heart muscle due to the altered relation between the inflamed endocardium and the blood that visits it. Tumultuous action, variability, reduplication of the second sound and altered (lengthened, it may be, or of altered tone, such as I know but cannot put to words), these are joint signs of this irritability. Tricuspid murmur in these circumstances may so soon be followed by mitral as to escape notice. But, given a previously healthy heart, early access to the patient, and, it must be added, due respect for the right ventricle, and care to discriminate between tricuspid and mitral, and there can be no doubt that the sign upon which Sibson laid so much stress is not seldom met with.

H. W., a boy of 11, was admitted to the Westminster Hospital October 24th of last year, having been ill three days with his first attack of rheumatism. Pain was in knees and ankles, and temperature $102^{\circ}$, but there was neither swelling nor redness of any joint, and on the fourth day of the illness, that is a few hours only after admission, the fever left him. After three days' residence the boy seemed well. The area of cardiac dulness was normal, and it was not until the fifth day from the first joint pain (26th) that anything abnormal was noticed of the heart. On that day the rhythm became uneven, and a slight systolic murmur (not blowing) was heard at the ensiform cartilage, less audible at the apex. Pulsewas 84 and ill sustained, varying in force, that is to say, remarkably when continuously felt over three or four minutes. A week later (November 6th) the tricuspid murmur was still audible with that rough beginning which some christen presystolic. At the apex the first sound was lengthened and murmurish. It happened with this boy as with the girl Edmunds, previously quoted, that upon repeated experiment the murmur was always lost in the erect posture.

Shortly after this patient, whom we were not able to retain long, a girl of 18 was admitted on the ninth day of her first attack of acute rheumatism. There was pericardial rubbing, and at the ensiform cartilage a distinct systolic (tricuspid) murmur. Both joint pains and pericardial friction quickly disappeared, and on the girl's discharge, after three weeks' residence, a soft apex murmur had taken the place of the rougher tricuspid bruit.

A third case might be quoted to the same effect, a boy of 10 , in his first attack of rheumatism with some heart pain. At first no cardiac murmur was audible, and the earliest physical sign of valve lesion was again tricuspid in seat and character.

And just now, in the nick of time, comes another boy, aged 12, in the third day of a slight rheumatic attack. A systolic murmur was audible at first at the ensiform cartilage : but after three days' continuance it shifted its place, and became distinctly mitral.

It is true that in practice we cannot afford to depend upon so precarious a sign as tricuspid murmur; true also that the signs we do trust we often fail to describe. Many have laboured at their description from Sibson to Potain, and all have consciously failed; they are to be learnt not from the book, but at the bedside. Thus there are many varieties of first sound, all of them more or less indicative of commencing endocarditis. The prolongation of such sound right up to the second is a precise definition enough. Not so "the accent" which begins it, while the several changes of quality -changes which every student soon learns to recognise for himself-he cannot impart to another. It is knowledge that is not transmissible, but remains each man's secret in 